\title{
ORIGINAL ARTILLE Comorbidities of mental and behavioral disorders in chemically dependent patients in different periods of abstinence
}

\author{
Comorbidades de transtorno mental e comportamental em pacientes \\ dependentes químicos em diferentes períodos de abstinência
}

Maria de Lourdes Pereira Costa', Luiz Carlos Marques de Oliveira²

\begin{abstract}
Objective: To assess the frequency of comorbidities of mental and behavioral disorders (CMBD) in psychoactive substance (PAS)-dependent patients with different periods of abstinence cared for at Alcohol and Other Drug Psychosocial Care Centers (CAPS-ad). Method: All patients under treatment in the two CAPS-ad of the city of Uberlândia-MG, between April and September 2010, were consecutively assessed. The ICD-10 symptom checklist was used to diagnose CMBD; additional information was obtained from interviews and medical records. The patients were divided according to duration of abstinence: $<1$ week (Group 1); 1-4 weeks (Group 2); and $>4$ weeks (Group 3). Results: Of all patients assessed, 62.8\% were diagnosed with CMBD, which were more frequent $(p<0.05)$ in Group $1(72 \%)$ than Group 3 (54.2\%), and both groups were similar to Group 2 (61\%). Depressive and anxiety disorders were more frequent among patients of Group 1. Mood disorders were more frequent ( $p$ $<0.05)$ in women [22/34 (65\%) vs. 54/154 (35.1\%)], whereas psychotic disorders were more frequent $(p=0.05)$ in men [16/154 (10.4\%) vs. 0]. The presence of CMBD was associated with more severe clinical conditions. Conclusions: The higher frequency of diagnosis of CMBD in patients of Group 1 may have resulted from the difficulties in distinguishing mental disorders that are due to PAS intoxication or withdrawal from those that are not. However, to make the diagnosis of $C M B D$, even during detoxification, can increase the likelihood of better response to treatment.
\end{abstract}

\section{Keywords}

Comorbidity, diagnosis, dual (psychiatry), dependency (psychology), alcoholism.

\section{RESUMO}

Objetivo: Avaliar a frequência de comorbidades de transtorno mental e comportamental (CTMC) em pacientes dependentes de substâncias psicoativas (SPA) em Centros de Atenção Psicossocial de Álcool e outras Drogas (CAPS-ad), com diferentes períodos de abstinência. Método: Avaliaram-se, consecutivamente, todos os pacientes que estavam em tratamento nos dois CAPS-ad de Uberlândia-MG, entre abril e setembro de 2010. Para o diagnóstico de

\footnotetext{
1 Universidade Federal de Uberlândia (UFU), Centro de Atenção Psicossocial de Álcool e Outras Drogas (CAPS-ad) David Capistrano da Costa Filho e Programa de Atenção à Pessoa com Dependência Química. 2 UFU, Faculdade de Medicina, CAPS-ad, Departamento de Clínica Médica.
}

Recebido em $7 / 5 / 2012$ Aprovado em $7 / 8 / 2012$
Address for correspondence: Luiz Carlos Marques de Oliveira Departamento de Clínica Médica Av. Pará, 1720, Bloco 2H, Campus Umuarama 38405-320 - Uberlândia, MG, Brazil Telefax: (55 34) 3218-2246 E-mail: oliveiralcm@ufu.br 


\section{Palavras-chave}

Comorbidade, diagnóstico duplo (psiquiatria), dependência (psicologia), alcoolismo.
CTMC, utilizou-se o Checklist de sintomas da CID-10; informações adicionais foram obtidas em entrevistas e em prontuários. Os pacientes foram divididos de acordo com o tempo de abstinência: < 1 semana (Grupo 1), 1-4 semanas (Grupo 2) e > 4 semanas (Grupo 3). Resultados: Dentre todos, $62,8 \%$ tiveram diagnóstico de CTMC, que foi mais frequente $(p<0,05)$ no Grupo 1 (72\%) do que no Grupo 3 (54,2\%); ambos os grupos foram semelhantes ao Grupo 2 (61\%). Transtornos depressivos e de ansiedade foram mais frequentes entre pacientes do Grupo 1. Transtornos de humor foram mais frequentes $(p<0,05)$ em mulheres $[22 / 34(65 \%)$ vs. 54/154 (35,1\%)], enquanto transtornos psicóticos foram mais frequentes $(p=0,05)$ em homens [16/154 (10,4\%) vs. 0]. CTMC associou-se a piores condições clínicas. Conclusões: Maior frequência de diagnóstico de CTMC entre pacientes do Grupo 1 pode ser decorrente das dificuldades de se diferenciar transtornos mentais que são decorrentes ou independentes da intoxicação ou suspensão da SPA. Porém, fazer o diagnóstico de CTMC, mesmo durante a desintoxicação, pode aumentar as chances de resposta ao tratamento.

\section{INTRODUCTION}

Substance use disorders (SUD), i.e., dependence on or abuse of a PAS, can be associated with other mental and behavioral disorders (MBD), which are known as co-occurring, dual diagnosis or comorbidities. Individuals with SUD associated with comorbidities of MBD (CMBD) had more severe symptoms, reported greater suffering and consequently sought treatment more often, when compared to those without comorbidities. However, patients with CMBD showed poorer adherence to treatment, frequent and faster relapses, a higher occurrence of social problems and decreased treatment compliance?.

Comorbidities of MBD range from "high-prevalence, low-impact" disorders such as depression and anxiety, to "low-prevalence, high-impact" severe mental illnesses such as psychosis and major mood disorders ${ }^{2}$. The causes of CMBD in SUD patients may include coincidence, common genetic vulnerability, common neural substrate, underlying shared origins, self-medication, and lifestyle ${ }^{2,3}$. Diagnosing CMBD in SUD patients is important because it enables both disorders to be treated. This treatment can be performed sequentially, simultaneously or in an integrated way, depending on the type and severity of the two disorders ${ }^{3-5}$.

The frequencies and interference of CMBD associated with SUD have been studied since the 1980s. The first major epidemiological study that assessed the prevalence of CMBD in alcohol and/or other drug-dependent individuals was conducted in the United States between 1980 and 1984 (Epidemiologic Catchment Area - ECA) 6 . This study showed a prevalence of CMBD in 37\% of alcohol-dependent individuals and in 53\% of other drug-dependent (excluding alcohol) individuals. Since then, clinical and epidemiological studies conducted in several countries have found high prevalences of CMBD associated with SUD, showing that the presence of CMBD in SUD individuals is the norm, rather than the exception ${ }^{7,8}$.

However, these studies show a wide variation in the prevalence of $C M B D$, which could be attributed to several factors. For instance, there is no consensus on the definition of comorbidity; narrow definitions commonly limit comorbidity to the co-occurrence of severe mental illness with concurrent substance use, while broad definitions can encapsulate all mental health disorders and any level and combination of substance use problems 4 . Additionally, the prevalence of CMBD may vary according to the type of study (clinical or epidemiological), the type of service where it was conducted, the assessment method used, sample socio-demographic characteristics, the drug availability in the community and the geographic region studied?.

Moreover, it may be difficult to separate psychiatric disorders from the symptoms of substance abuse, intoxication or withdrawal. Therefore, the Diagnostic and Statistical Manual of Mental Disorders, Fourth Edition (DSM-IV) of the American Psychiatric Association recommends that the assessment to diagnose CMBD should be performed with individuals who have been abstinent for at least four weeks ${ }^{3}$. However, many studies did not describe the duration of abstinence before the CMBD was diagnosed ${ }^{6,10}$, or they showed a variation in the period of abstinence examined ${ }^{11-15}$.

A literature review was conducted and there were no studies that assessed the prevalence of CMBD among SUD patients according to the period of abstinence, using the same assessment method to diagnose comorbidities. In view of the relevance of this theme, the present study aimed to assess and compare the prevalence of diagnosis of CMBD in patients with chemical dependency (CD) cared for at Alcohol and Other Drug Psychosocial Care Centers (CAPS-ad, in the Portuguese acronym), according to the duration of abstinence, and to compare socio-demographic data and some clinical conditions between patients with and those without CMBD. 


\section{METHODS}

\section{Ethical issues}

The present study was approved by the Uberlândia Federal University Research Ethics Committee (Official Opinion 156/10) and the research was conducted according to the standards required by the Declaration of Helsinki. An informed consent form was signed by each patient for their participation. Individual interviews were conducted in a reserved location.

\section{Setting}

This cross-sectional study was conducted in both CAPS-ad II in the city of Uberlândia, MG, Brazil, between April and September 2010. The CAPS-ad II are outpatient care institutions that serve adult patients ( $\geq 18$ years of age) with disorders resulting from the abuse of or dependence on PAS.

Health care is provided by multi-professional teams in two daily shifts (morning/afternoon) in one of the CAPS-ad and in three shifts (morning, afternoon and evening until 9:00 $\mathrm{pm}$ ) in another one, from Mondays through Fridays. After being received without a previous appointment and assessed by professionals, patients are provided the type of treatment that meets their needs, i.e. intensive, semi-intensive and non-intensive care. Patients in crisis or in need of detoxification are referred to locations where they can be hospitalized, i.e. municipal health units or the Uberlândia Federal University Clinical Hospital. In 2010, a total of 650 individuals were registered to be cared for in the two CAPS-ad.

\section{Procedures}

All patients under treatment in the two CAPS-ad during the period of data collection were approached consecutively. The research objectives were explained to them and they were subsequently invited to participate in the study. None of the patients approached refused to participate. Patients who were under the effect of PAS, experiencing a crisis of abstinence or severe psychotic episodes, taking high psychoactive drug doses that hindered diagnostic assessment, and those with dementia were excluded from this study. Interviews were conducted by one of the authors (Costa-MLP), a psychologist with experience in the treatment of patients with mental disorders, including SUD patients. Prior to data collection, this researcher was trained to use the ICD-10 symptom checklist for MBD, version 1.1, with patients of the CAPS-ad. The results obtained were compared with the psychiatric assessment noted in the medical records and there was a good level of agreement between them. Mean assessment time for each patient was one hour and fifty minutes.

\section{Main outcomes measures}

First of all, a structured questionnaire was used to obtain socio-demographic data (age, sex, marital status, self-reported skin color, level of education and monthly minimum wage); and information about childhood (family composition, family disruption, maltreatment and sexual abuse), about PAS use (onset, PAS used, previous treatment for CD) and about mental health (perception of other MBD apart from CD or having such condition, onset and symptoms present, previous treatments, psychiatric hospitalizations, and suicide attempts). The ICD-10 symptom checklist for MBD, version 1.1, was used to diagnose mental disorders, including SUD. This checklist is a semi-structured instrument translated by Oliveira and Cordioli' ${ }^{16}$ and used to assess psychiatric symptoms and syndromes in the F0 to F6 categories. In addition, this checklist is divided into categories that comprise a list of symptoms and states that should be either included in or excluded from each disorder. These lists are followed by instructions that can help the user to consider other possible syndromes and, consequently, the use of other checklist categories. These categories also offer the possibility of recording the onset, severity and duration of the syndrome, in addition to the number of episodes. The ICD-10 symptom checklist was found to be a reliable diagnostic tool (overall kappa 0.72), and this tool can be used by psychiatrists and psychologists without previous training ${ }^{17}$. Symptoms of anxiety, depression, hallucinations and delirium were not considered to be positive when they were exclusively associated with recent PAS use, but rather when they were present during a certain period, according to the duration and number of episodes throughout life.

Mental status assessment was conducted according to behavioral observations and questions made during the interview, including the following areas: consciousness, memory, intellect, speech, thought process and content, perception, mood, affectivity and appearance, based on the norms proposed by international diagnostic assessment directives ${ }^{18}$. Data collection from medical records was performed aiming to search for additional sources of information about the patient, such as data on previous and/or current treatment and information about mental health.

After the interviews were conducted, patients were divided into three groups: those with a period of abstinence shorter than one week (Group 1), between one and four weeks (Group 2) and longer than four weeks (Group 3).

\section{Data analyses}

Data were organized, tabulated and analyzed with the Statistical Package for the Social Sciences software (SPSS version 17.0, IBM Inc., Chicago, IL, USA, 2008). A descriptive analysis was made to characterize the sample. The frequencies of CMBD were compared between the three groups and the clinical and socio-demographic variables were compared between patients with and without CMBD. Chi-square test or Fisher's exact test was used to compare the frequencies of the variables analyzed. Student's t test was used to compare mean ages. A $p \leq 0.05$ was considered to be significant. 


\section{RESULTS}

In the present study, a total of 188 patients were analyzed, of which 154 (81.9\%) were males and 34 (18.1\%) were females, with a mean age and standard deviation of $38.5 \pm 9.9$ years, varying between 18 and 73 years. All of them met the diagnostic criteria for PAS dependence syndrome: 88 (46.8\%) had multiple drug dependence, 87 (46.3\%) were dependent on alcohol exclusively, 10 (5.3\%) on cocaine, 2 (1.1\%) on cannabinoids and 1 (0.5\%) on sedatives; in addition, 134 (71.3\%) were also dependent on tobacco.

Of all patients, 118 (62.8\%) were diagnosed with a certain MBD; 40.4\% met the diagnostic criteria for mood disorders, with a predominance of depressive disorders (33.0\%); 18.6\% were diagnosed with neurotic disorders, stress and somatoform disorders, with a predominance of anxiety disorders (13.8\%); 10.1\% met the diagnostic criteria for disorders of adult personality and behavior with a predominance of dissocial personality disorders (4.2\%); and 8.5\%, for schizophrenia, schizotypal personality disorder and persistent delusional disorder, with a predominance of schizophrenia (5.3\%). A total of 28 (14.9\%) patients were diagnosed with more than one CMBD (Table 1).

Diagnoses of CMBD were more frequent $(p=0.04)$ in Group 1 patients (72.0\%) than those in Group 3 (54.2\%), and there were no significant differences between Group 1 and Group 2 patients (61.0\%), nor between Group 2 and Group 3 patients. The frequencies of depressive disorders or other anxiety disorders were numerically higher in Group 1 patients than Group 3 patients, without a significant difference between them. However, when these two variables were analyzed together, they were more frequent $(p=0.00)$ in Group 1 (46\%) than in Group 3 (25\%). The frequencies of persistent delusional disorder, schizoaffective, schizotypal and schizophrenia analyzed together were higher ( $p=0.04)$ in Group 3 (10 [13.9\%]) than in Group 1 (3 [4\%]) and there were no differences between Group 2 (3 [7.3\%]) and Group 1 or Group 3 (Table 1). Mood disorders were more frequent in women, whereas psychotic disorders were more frequent in men (Table 2).

There were no significant differences in the socio-demographic characteristics assessed between patients with and without CMBD, nor among patients with different periods of abstinence. The majority of patients assessed reported they were single/divorced/separated (64.9\%), had a primary school level of education or lower, were white, had a religion, received a monthly personal income lower than one minimum wage and were unemployed (Table 3).

Child maltreatment, including sexual abuse, was more frequent $(p=0.00)$ in patients with a CMBD (80 [67.8\%] vs. 30 [42.8\%]). By comparing patients with and those without

Table 1. Frequencies of comorbidities of mental and behavioral disorders (CMBD) in the patients assessed $(n=188)$ : Group 1 ( $n=75)$, Group $2(n=41)$ and Group $3(n=72)$

\begin{tabular}{|c|c|c|c|c|c|c|c|c|}
\hline \multirow{2}{*}{ MBD associated with CD } & \multicolumn{2}{|c|}{ Group 1} & \multicolumn{2}{|c|}{ Group 2} & \multicolumn{2}{|c|}{ Group 3} & \multicolumn{2}{|c|}{ Total } \\
\hline & $n$ & $\%$ & $n$ & $\%$ & $n$ & $\%$ & $\mathrm{n}$ & $\%$ \\
\hline \multicolumn{9}{|l|}{ Mood disorders } \\
\hline Depressive episode (F32) & 19 & 25.3 & 11 & 26.8 & 13 & 18.0 & 43 & 22.9 \\
\hline Recurrent depressive disorder (F33) & 11 & 14.7 & 3 & 7.3 & 5 & 6.9 & 19 & 10.1 \\
\hline Persistent mood disorder (F 34) & 5 & 6.7 & 3 & 7.3 & 3 & 4.2 & 11 & 5.8 \\
\hline Bipolar affective disorder (F 31) & 0 & & 2 & 4.9 & 1 & 1.4 & 3 & 1.6 \\
\hline \multicolumn{9}{|l|}{ Neurotic, stress-related and somatoform disorders } \\
\hline 0ther anxiety disorders ( $F 41$ ) & 16 & 21.3 & 3 & 7.3 & 7 & 9.7 & 26 & 13.8 \\
\hline Dissociate disorders (F 44) & 1 & 1.3 & 1 & 2.4 & 2 & 2.8 & 4 & 2.1 \\
\hline Specific phobias (F 40.2) & 1 & 1.3 & 1 & 2.4 & 0 & & 2 & 1.1 \\
\hline Reaction to severe stress and adjustment disorders (F43) & 1 & 1.3 & 1 & 2.4 & 0 & & 2 & 1.1 \\
\hline Obsessive-compulsive disorder (F 42) & 0 & & 1 & 2.4 & 0 & 0 & 1 & 0.5 \\
\hline \multicolumn{9}{|l|}{ Disorders of adult personality and behavior } \\
\hline Dissocial personality disorder (F 60.2) & 5 & 6.7 & 1 & 2.4 & 2 & 2.8 & 8 & 4.2 \\
\hline Emotionally unstable personality disorder (F 60.3) & 3 & 4.0 & 1 & 2.4 & 2 & 2.8 & 6 & 3.2 \\
\hline Schizoid (F 60.1); Dependent (F 60.7); 0thers (F 60.8) & 2 & 2.7 & 3 & 7.3 & 0 & & 5 & 2.7 \\
\hline \multicolumn{9}{|l|}{ Schizophrenia, schizotypal disorder and delusional } \\
\hline Schizophrenia (F 20) & 2 & 2.7 & 2 & 4.9 & 6 & 8.3 & 10 & 5.3 \\
\hline Persistent delusional disorder (F 22) & 1 & 1.3 & 0 & & 2 & 2.8 & 3 & 1.6 \\
\hline Schizoaffective disorder (F 25) & 0 & & 1 & 2.4 & 1 & 1.4 & 2 & 1.1 \\
\hline Schizotypal disorder (F 21) & 0 & & 0 & & 1 & 1.4 & 1 & 0.5 \\
\hline More than one comorbidity & 13 & 17.3 & 9 & 22.0 & 6 & 8.3 & 28 & 14.9 \\
\hline Total & 54 & $72.0^{*}$ & 25 & 61.0 & 39 & $54.2^{*}$ & 118 & 62.8 \\
\hline
\end{tabular}

${ }^{*} p=0.04$. Chi-square test: Group $1>$ Group 3. 
$C M B D$, there were no statistically significant differences in the frequencies of family members who showed PAS use/ abuse, occurrences of disrupted families or children staying only with the mother after family disruption (Table 4).

Among the clinical conditions assessed, the frequencies of the following aspects were significantly higher in patients with CMBD than in those without comorbidities: external cause injuries, perception of having an MBD other than CD or of having a certain psychological problem, being involved in fights and aggressions, hospitalizations in psychiatric hospitals or in general hospitals, legally prescribed drugs use, suicide attempts and previous CD treatment (Table 5).

Table 2. Frequency of comorbidities of mental and behavioral disorders (MBD) associated with chemical dependency among males (n $=154)$ and females $(n=34)$

\begin{tabular}{|c|c|c|c|c|c|c|c|}
\hline \multirow{2}{*}{ MBD } & \multicolumn{2}{|c|}{$\begin{array}{l}\text { Female } \\
(n=34)\end{array}$} & \multicolumn{2}{|c|}{$\begin{array}{c}\text { Male } \\
(n=154)\end{array}$} & \multirow[t]{2}{*}{$\mathrm{p}^{*}$} & \multicolumn{2}{|c|}{$\begin{array}{c}\text { Total } \\
(n=188)\end{array}$} \\
\hline & $\mathrm{n}$ & $\%$ & $\mathrm{n}$ & $\%$ & & $\mathrm{n}$ & $\%$ \\
\hline Mood disorders & 22 & 65.0 & 54 & 35.1 & 0.00 & 76 & 40.4 \\
\hline Neurotic disorders associated with stress and somatoform disorders & 8 & 23.5 & 27 & 17.5 & 0.57 & 35 & 18.6 \\
\hline Personality disorders & 5 & 14.7 & 14 & 9.1 & 0.52 & 19 & 10.1 \\
\hline $\begin{array}{l}\text { Schizophrenia, schizotypal personality disorder and persistent delusional } \\
\text { disorder }\end{array}$ & 0 & & 16 & 10.4 & 0.05 & 16 & 8.5 \\
\hline More than one comorbidity & 8 & 23.5 & 20 & 13.0 & 0.19 & 28 & 14.9 \\
\hline Total & 25 & 73.5 & 93 & 60.4 & 0.22 & 118 & 62.8 \\
\hline
\end{tabular}

* Chi-square test or Fisher exact test.

Table 3. Socio-demographic characteristics of the patients assessed ( $n=188)$, with $(n=118)$ or without $(n=70)$ comorbidities of mental and behavioral disorders (CMBD) associated with chemical dependency

\begin{tabular}{|c|c|c|c|c|c|c|c|}
\hline \multirow{2}{*}{ Variables } & \multicolumn{2}{|c|}{ With CMBD } & \multicolumn{2}{|c|}{ Without CMBD } & \multirow{2}{*}{$\mathbf{p}^{*}$} & \multicolumn{2}{|c|}{ Total } \\
\hline & $\mathrm{n}$ & $\%$ & $\mathrm{n}$ & $\%$ & & n & $\%$ \\
\hline Age (mean $\pm S D)$ & \multicolumn{2}{|c|}{$37.9 \pm 9.1$} & \multicolumn{2}{|c|}{$39.4 \pm 11.2$} & 0.33 & \multicolumn{2}{|c|}{$38.5 \pm 9.9$} \\
\hline Sex & & & & & 0.22 & & \\
\hline Male & 93 & 78.8 & 61 & 87.1 & & 154 & 81.9 \\
\hline Female & 25 & 21.2 & 9 & 12.8 & & 34 & 18.1 \\
\hline Skin color & & & & & 0.74 & & \\
\hline White & 80 & 67.8 & 51 & 72.8 & & 131 & 69.7 \\
\hline Mixed & 29 & 24.6 & 14 & 20.0 & & 43 & 22.9 \\
\hline Black & 9 & 7.6 & 5 & 7.1 & & 14 & 7.4 \\
\hline Practices a religion & & & & & 0.75 & & \\
\hline Yes & 92 & 78.0 & 59 & 84.3 & & 151 & 80.3 \\
\hline No & 26 & 22.0 & 11 & 15.7 & & 37 & 19.7 \\
\hline Marital status & & & & & 0.10 & & \\
\hline Single & 48 & 40.7 & 20 & 28.6 & & 68 & 36.2 \\
\hline Married/cohabitating & 35 & 29.7 & 31 & 44.3 & & 66 & 35.1 \\
\hline Divorced/separated & 35 & 29.7 & 19 & 27.1 & & 54 & 28.7 \\
\hline Level of education & & & & & 0.78 & & \\
\hline$\leq$ primary school & 83 & 70.3 & 52 & 74.3 & & 135 & 71.8 \\
\hline$\geq$ secondary school & 35 & 29.7 & 18 & 25.7 & & 53 & 28.2 \\
\hline Occupation & & & & & 0.69 & & \\
\hline Unemployed & 56 & 47.4 & 31 & 44.3 & & 87 & 46.3 \\
\hline Formal work & 29 & 24.6 & 19 & 27.1 & & 48 & 25.5 \\
\hline Informal work & 18 & 15.2 & 14 & 20.0 & & 32 & 17.0 \\
\hline Retired/Beneficiary & 15 & 12.7 & 6 & 8.6 & & 21 & 11.2 \\
\hline Personal income ${ }^{* *}$ & & & & & 0.40 & & \\
\hline $0 \mathrm{I}-1$ & 85 & 72.0 & 48 & 68.6 & & 133 & 70.7 \\
\hline $11-13$ & 28 & 23.7 & 21 & 30.0 & & 49 & 26.1 \\
\hline$>4$ & 5 & 4.2 & 1 & 1.4 & & 6 & 3.2 \\
\hline
\end{tabular}

SD: standard deviation (years). CD: Chemical dependency. ${ }^{*}$ Student's t test or chi-square test (with comorbidity = without comorbidity). ${ }^{* *}$ Minimum wage. 
Table 4. Data on the childhood of patients assessed $(n=188)$, with $(n=118)$ or without $(n=70)$ comorbidities of mental and behavioral disorders (CMBD) associated with chemical dependency

\begin{tabular}{|c|c|c|c|c|c|c|c|}
\hline \multirow{2}{*}{ Variables } & \multicolumn{2}{|c|}{ With CMBD } & \multicolumn{2}{|c|}{ Without CMBD } & \multirow{2}{*}{$\mathrm{p}$} & \multicolumn{2}{|c|}{ Total } \\
\hline & $\mathrm{n}$ & $\%$ & $\mathrm{n}$ & $\%$ & & $\mathrm{n}$ & $\%$ \\
\hline Maltreatment during childhood & 59 & 50.0 & 23 & 32.8 & $0.03^{*}$ & 82 & 43.6 \\
\hline Sexual abuse during childhood & 21 & 17.8 & 7 & 10.0 & 0.21 & 28 & 14.9 \\
\hline PAS use by family members & 91 & 77.1 & 52 & 74.3 & 0.79 & 143 & 76.1 \\
\hline Family structure & & & & & 0.70 & & \\
\hline Parental separation & 43 & 36.4 & 25 & 35.7 & & 68 & 36.2 \\
\hline Nuclear family & 28 & 27.3 & 21 & 30.0 & & 49 & 26.1 \\
\hline Death of father/mother & 31 & 26.7 & 17 & 24.3 & & 48 & 25.8 \\
\hline Abandonment & 8 & 6.9 & 5 & 7.2 & & 13 & 7.0 \\
\hline Single mother & 8 & 6.8 & 2 & 2.8 & & 10 & 5.3 \\
\hline Family disruption & 90 & 76.3 & 49 & 70.0 & 0.44 & 139 & 73.9 \\
\hline Stayed with the mother & 51 & 56.7 & 28 & 57.1 & & 79 & 56.8 \\
\hline Stayed with relatives & 21 & 23.3 & 13 & 26.5 & & 34 & 24.5 \\
\hline Stayed with the father & 9 & 10.0 & 5 & 10.2 & & 14 & 10.1 \\
\hline Adoption & 4 & 4.4 & 1 & 2.0 & & 5 & 3.6 \\
\hline Stayed with non-relatives & 4 & 4.4 & 1 & 2.0 & & 5 & 3.6 \\
\hline Shelter & 1 & 1.1 & 1 & 2.0 & & 2 & 1.4 \\
\hline
\end{tabular}

Chi-square test; ${ }^{*}$ with CMBD > without CMBD. Percentages calculated considering the valid responses.

Table 5. Clinical characteristics of the patients assessed $(n=188)$, with $(n=118)$ or without $(n=70)$ comorbidities of mental and behavioral disorders (CMBD) associated with chemical dependency

\begin{tabular}{|c|c|c|c|c|c|c|c|}
\hline \multirow{2}{*}{ Variables } & \multicolumn{2}{|c|}{ With CMBD } & \multicolumn{2}{|c|}{ Without CMBD } & \multirow{2}{*}{ p } & \multicolumn{2}{|c|}{ Total } \\
\hline & $\mathrm{n}$ & $\%$ & n & $\%$ & & $\mathrm{n}$ & $\%$ \\
\hline External cause injuries ${ }^{* *}$ & 100 & 84.7 & 48 & 68.6 & $0.01^{*}$ & 148 & 78.7 \\
\hline Perception of having other MBD & 100 & 84.7 & 26 & 37.1 & $0.00^{*}$ & 126 & 67.0 \\
\hline Perception of having psychological disorder & 94 & 79.7 & 31 & 44.3 & $0.00^{*}$ & 125 & 66.5 \\
\hline Fights and aggressions & 74 & 62.7 & 30 & 42.8 & $0.01^{*}$ & 104 & 55.3 \\
\hline Hospitalization in general hospital & 69 & 58.5 & 29 & 41.4 & $0.03^{*}$ & 98 & 52.1 \\
\hline Regular psychoactive drug use & 96 & 81.4 & 26 & 37.1 & $0.00^{*}$ & 122 & 64.9 \\
\hline Suicide attempt(s) & 54 & 45.8 & 11 & 15.7 & $0.00^{*}$ & 65 & 34.6 \\
\hline Previous CD treatment & 104 & 88.1 & 49 & 70.0 & $0.04^{*}$ & 153 & 81.4 \\
\hline \multicolumn{8}{|l|}{ Controlled environment } \\
\hline Therapeutic community & 58 & 49.2 & 26 & 37.1 & 0.95 & 84 & 44.7 \\
\hline Penitentiary & 39 & 33.0 & 17 & 24.3 & 0.91 & 56 & 28.2 \\
\hline Hospitalization in psychiatric hospital & 53 & 44.9 & 14 & 20.0 & $0.00^{*}$ & 67 & 35.6 \\
\hline
\end{tabular}

${ }^{*}$ Chi-square test (with morbidity > without comorbidity). ** With CMBD: traffic accident $(N=47)$, sharp object injury $(N=43)$, frearm injury $(N=10)$. Without CMBD: traffic accident $(N=30)$, sharp object injury; $(N=12)$, frearm injury $(\mathrm{N}=6)$.

\section{DISCUSSION}

\section{Frequency of diagnosis of CMBD associated with CD}

Of all patients, two thirds of them had a certain diagnosis of CMBD associated with CD. These results are similar to those found in a clinical study conducted in Toronto, Canada, in which the Diagnostic Interview Schedule was used to make the diagnosis of comorbidities (68.4\%) ${ }^{11}$ and to another performed in São Paulo, Brazil, in which authors used the same assessment tool adopted in this study $(67.7 \%)^{10}$. Furthermo- re, in the latter study, the frequencies of the following diagnoses were also similar to those found in the present study: depressive disorders (33.9\%), anxiety disorders (11.5\%), personality disorders (16.1\%) and schizophrenia (2.6\%).

In Group 1,72\% of patients had a certain diagnosis of $C M B D$, a result that was lower than those observed in another clinical study carried out in Alaska, USA, conducted in patients with the same period of abstinence in an alcohol detoxification center (82\%) ${ }^{14}$. This study used the Brief Symptom Inventory as a diagnostic tool and showed frequencies of diagnoses of depressive disorders (74.2\%) and anxiety 
disorders (73.5\%) that were higher than those observed in the present study.

Of all patients with a period of abstinence longer than one week (Groups 2 and 3), 56.6\% were diagnosed with CMBD. These results were lower than those found in a study conducted in the city of São Paulo, Brazil, in which patients with CD showed the same period of abstinence $(72 \%)^{12}$. This study used the Research Diagnostic Criteria as an assessment tool and found frequencies of depressive disorders (32\%), anxiety disorders (8\%), dissocial personality disorder (2\%) and schizophrenia (8\%) that were similar to those of the present study.

In Group 3, 54.2\% of patients had a certain diagnosis of $C M B D$, a frequency that was higher than that found by Heilig et al. ${ }^{13}$ in a study performed in Sweden in patients with CD and a period of abstinence longer than three weeks (42\%), using the Structured Clinical Interview for DSM disorders.

The frequency of diagnosis of CMBD in Group 1 patients was higher than that in Group 3 patients, and the higher frequencies of depressive disorders and anxiety disorders in the former were what mainly distinguished one group from the other. High levels of anxiety or depression can be produced by the effects of PAS in the stage of intoxication or withdrawal of such substances ${ }^{6,19}$. Such effects can remain for some days and disappear, unless these disorders are primary and continue to persist after many weeks of abstinence. For these reasons, it is recommended that a patient's follow-up should occur during a significant time for the diagnosis of other MBD to be reliable, and that this time could be different, depending on the PAS used'. A higher frequency of these disorders in Group 1 was observed in the present study, even if such diagnoses were considered to be positive when found throughout a certain period of time, rather than associated with recent PAS use exclusively.

Individuals seeking treatment due to SUD frequently have a history of recent PAS use and difficulties maintaining abstinence. The great challenge of clinicians who care for SUD patients is to distinguish symptoms caused by PAS intoxication or withdrawal from those that are primary mental disorders. Symptoms related to drug abuse, such as nervousness, tension, agitation, depressed mood and loss of motivation, may also be symptoms included in the diagnostic criteria for mental disorders, e.g. generalized anxiety disorder and depressive disorder ${ }^{3}$. For these reasons, the frequency of diagnosis of CMBD in these patients may be overestimated.

However, it is important to identify these mood and/or anxiety disorders in patients with CD and they should not remain untreated, according to the assumption that these symptoms are due to PAS intoxication or abstinence. Severe mood disorders that are not treated can lead to relapses and even death by suicide ${ }^{19}$. In addition, it is believed that making a diagnosis of CMBD is important, even in the period of detoxification, as this increases the likelihood of individuals' needs being adequately met and of better adherence to treatment ${ }^{14}$.

In this study, it was observed that the frequencies of diagnoses of schizophrenia, persistent delusional disorders, schizoaffective disorders and schizotypal disorders were higher in Group 3 than in Group 1. This could be associated with the fact that patients experiencing a crisis were excluded, due to the difficulty in distinguishing previous psychotic symptoms from psychotic symptoms induced by PAS use or abstinence'. Another reason for this could be the fact that patients who have more severe MBD are referred to psychiatric institutions to be hospitalized when it is necessary and they only return to the CAPS-ad for CD treatment after longer periods of abstinence have passed.

Mood disorders, especially depressive disorders, were more frequent in women. In several other studies, it was also observed that depression is more common in women than men and that two thirds of women with SUD first have depression?. In these cases, PAS could have been used as selfmedication. Psychotic disorders were more frequent in men, which is in agreement with what has been described in another study².

\section{Socio-demographic data of the patients assessed}

With regard to the socio-demographic data analyzed, the results of the present study are similar to those observed in other Brazilian studies conducted in individuals with $C D$ undergoing treatment, such as the predominance of male patients $^{12,20}$, with a mean age of approximately 35 years ${ }^{11,20}$, white, not married ${ }^{12}$, and with incomplete or complete primary education ${ }^{20}$. PAS use has been found to negatively affect conjugal relationships, with higher risks of violent behavior in couples, resulting in separations ${ }^{21}$. The large number of unemployed individuals or informal workers, with a personal income predominantly lower than one minimum wage, and their low level of education could reflect the social impairment of these patients, who show higher risks of psychosocial problems such as school and work negligence and difficulties in assuming responsibilities ${ }^{21}$. The low levels of education and financial income could also be due to characteristics of the patients who usually seek the public health care network, which serves the portion of the population that does not have access to any other type of health care.

The majority of patients reported they had a religion; patients undergoing SUD treatment frequently seek a religion. It is believed that religiosity has an inhibitory effect on PAS use, encourages abstinence, raises self-esteem and promotes new social inclusion 22 .

There were no significant differences in socio-demographic data between patients with and without CMBD. These results differ from those described in a review study which found that patients with CMBD associated with SUD more frequently show loss of productivity, difficulties in 
maintaining jobs and a worse level of global functioning than those without comorbidities, imposing a greater economic burden on their families'.

\section{Conditions associated with the patients' childhood}

Child maltreatment, including sexual abuse, was more frequent in patients with CMBD. There could be a close relationship between maltreatment and adverse conditions during childhood, with symptoms of depression, mania23, some personality disorders in early adulthood ${ }^{24}$, high risk of interpersonal difficulties during adolescence and suicidal behavior ${ }^{25}$. Children and adolescents who were exposed to negative experiences could have feelings of abandonment and emotional problems, when PAS use becomes a way of avoiding psychological suffering and a relief from anxiety and anger ${ }^{26}$.

Similar high frequencies of PAS use in family members and of family disruption in patients with or without CMBD were observed. A review study found that these two conditions are risk factors for PAS use ${ }^{27}$. The majority of patients stayed with the mother after family disruption. There is clinical evidence that the absence of the father or impairment of paternal function aspects could be a relevant factor for the onset and maintenance of SUD ${ }^{27}$. These adverse conditions can be interrelated and consequently hinder an individual's development, which may contribute to the appearance of CMBD and to PAS use disorders.

\section{Aspects associated with the clinical conditions assessed}

Patients with CMBD reported external cause injuries and suicide attempts more frequently. Individuals with mental illness, especially more severe disorders, and with concurrent SUD show a higher prevalence of violent behavior and personal harms ${ }^{28}$. In addition, depressive disorders (major depressive episode or dysthymia) influence cognitions and behaviors associated with suicide, regardless of the presence of PAS use disorders, and the risk of suicide in certain individuals can be increased by the presence of SUD ${ }^{29}$. Furthermore, the risk of mood disorder, SUD and suicidal behavior may increase in patients who have anxiety disorders and use PAS as self-medication to relieve symptoms ${ }^{30}$.

Patients with CMBD more frequently perceived that they had a certain mental disorder or psychological problems apart from CD, were involved in fights and aggressions, were hospitalized in a general or psychiatric hospital, used legally prescribed drugs and underwent previous CD treatments. In other studies it was observed that patients with CMBD, especially those with more severe disorders, may have higher rates of aggression, detention due to illegal acts, suicide, relapses, spending on treatment, re-hospitalizations, longer hospitalization periods and greater medical service use?

\section{Clinical implications}

The present study revealed a high frequency of CMBD among patients with CD who sought the CAPS-ad, and these diagnoses need to be made to optimize treatment. The relevance of waiting for at least one month of abstinence before a diagnosis of CMBD can be defined should be emphasized, especially when it comes to diagnoses of depressive disorders and anxiety disorders. However, diagnosing $C M B D$, even in the period of detoxification, can increase the likelihood of individual needs being adequately met and of better adherence to treatment. As this study had a cross-sectional design, patients in Groups 1 and 2 were not reassessed to confirm diagnoses after longer periods of abstinence. This should be performed in future cohort studies.

\section{Study limitations}

One of the limitations of the present study was the fact that a specific sample was assessed. Patients being treated in CAPS-ad usually have a more severe condition. Consequently, the results found may not represent what occurs in SUD individuals in the population. The assessment of patients by a single researcher did not enable an agreement of diagnosis to be obtained. However, it is believed that the use of a standardized tool could reduce reliability bias.

\section{CONCLUSIONS}

The results of the present study show that among patients who sought treatment in the CAPS-ad: 1) approximately two thirds were diagnosed with a certain CMBD, and the frequency of such diagnoses was higher in patients with a shorter period of abstinence; 2 ) depressive disorders and anxiety disorders were more frequent in patients with shorter periods of abstinence; 3 ) mood disorders were more frequent in women, while psychotic disorders were more frequent in men; 4) patients with a diagnosis of CMBD more frequently experienced maltreatment during childhood, had external cause injuries, perceived that they had a certain mental disorder or psychological problem apart from CD, were involved in fights and aggressions, were hospitalized in general or psychiatric hospitals, used legally prescribed drugs and had a higher number of suicide attempts; 5) there were no differences in socio-demographic data between patients with and without CMBD.

\section{CONFLICTS OF INTEREST}

Authors declared there were no conflicts of interest. 


\section{REFERENCES}

1. Brems C, Johnson ME. Clinical implications of the co-occurrence of substance use and other psychiatric disorders. Prof Psychol Res Pr. 1997;28(5):437-47.

2. Canaway R, Merkes M. Barriers to comorbidity service delivery: the complexities of dual diagnosis and the need to agree on terminology and conceptual frameworks. Aust Health Rev. 2010;34(3):262-8.

3. Langås AM, Malt UF, Opjordsmoen S. Comorbid mental disorders in substance users from a single catchment area - a clinical study. BMC Psychiatry. 2010;11(25):1-12.

4. Merkes $M$, Lewis $V$, Canaway $R$. Supporting good practice in the provision of services to people with comorbid mental health and alcohol and other drug problems in Australia: describing key elements of good service models. BMC Health Serv Res. 2010;10(325):1-10.

5. Kelly MT, Daley DC, Douaihy AB. Treatment of substance abusing patients with comorbid psychiatric disorders. Addict Behav. 2012;37(1):11-24.

6. Regier DA, Farmer ME, Rae DS, Locke BZ, Keith SJ, Judd LL, et al. Comorbidity of mental disorders with alcohol and other drug abuse. Results from the Epidemiologic Catchment Area (ECA) Study. JAMA. 1990;264(19):2511-8.

7. Chou SP, Lee HK, Cho MJ, Park JI, Dawson DA, Grant BF. Alcohol use disorders, nicotine dependence, and co-occurring mood and anxiety disorders in the United States and South Korea - A cross-national comparison. Alcohol Clin Exp Res. 2012;36(4):654-62.

8. Perron BE, Bunger A, Bender K, Vaughn MG, Howard MO. Treatment guidelines for substance use disorders and serious mental illnesses: do they address c0-occurring disorders? Subst Use Misuse. 2010;45(7-8):1262-78.

9. Zaleski M, Laranjeira RR, Marques ACPR, Ratto L, Romano M, Alves HNP, et al. Diretrizes da Associação Brasileira de Estudos do Álcool e outras Drogas (ABEAD) para o diagnóstico e tratamento de comorbidades psiquiátricas e dependência de álcool e outras substâncias. Rev Bras Psiquiatr. 2006;28(2):142-8.

10. Palhares-Alves HN, Laranjeira R, Nogueira-Martins LA. A pioneering experience in Brazil: the creation of a support network for alcohol and drug dependent physicians. Rev Bras Psiquiatr. 2007;29(3):258-61.

11. Ross HE, Glaser FB, Germanson T. The prevalence of psychiatric disorders in patients with alcohol and other drug problems. Arch Gen Psychiatry. 1988;45(11):1023-31.

12. Silveira DX, Jorge MR. Comorbidade psiquiátrica em dependentes de substâncias psicoativas: resultados preliminares. Rev Bras Psiquiatr. 1999;21(3):145-51.

13. Heilig M, Forslund k, Asberg M, Rydberg U. The dual-diagnosis concept used by Swedish social workers: limited validity upon examination using a structured diagnostic approach. Eur Psychiatry. 2002;17(6):363-5.

14. Johnson ME, Brems C, Mills ME, Fisher DG. Psychiatric symptomatology among individuals in alcohol detoxification treatment. Addict Behav. 2007;32(8):1745-52.

15. Van Emmerik-van Oortmerssen K, Van de Glind G, Van den Brink W, Smit F, Crunelle CL, Swets $M$, et al. Prevalence of attention-deficit hyperactivity disorders in substance use disorder patients: a meta-analysis and meta-regression analysis. Drug Alcohol Depend. 2012;122(1-2):11-9.
16. Janca A, Üstün TB, Van Drimmelen JV, Dittmann V, Isaac M. Checklist de sintomas do CID-10 para transtornos mentais. Versão 1.1. Tradução para o português de Oliveira R e Cordioli AV. Genebra: OMS; 1994. p. 24. Disponível em: http://www.ufrgs.br/psiq/chklist. pdf. Acesso em: 15 fev. 2010.

17. Sartorius N, Janca A. Psychiatric assessment instruments developed by the World Health Organization. Soc Psychiatry Psychiatr Epidemiol. 1996;31(2):55-69.

18. Mezzich JE, Berganza CE, Von Cranach M, Jorge MR, Kastrup MC, Murthy RS, et al. Associação Mundial de Psiquiatria. Diretrizes Internacionais para Avaliação Diagnóstica (IGDA). Tradução para o português de Souza SJ, Ceconi JP e Stefanello S. Campinas, SP; 2004. p. 48. Disponível em: http://www.abpbrasil.org.br/departamentos/coordenadores/coordenador/noticias/imagens/associacao_mundial_psiquiatria.pdf. Acesso em: 15 fev. 2010.

19. Grant BF, Stinson FS, Dawson DA, Chou SP, Dufour MC, Compton W, et al. Prevalence and co-occurrence of substance use disorders and independent mood and anxiety disorders. Results from the National Epidemiologic Survey on Alcohol and Related Conditions. Arch Gen Psychiatry. 2004;61(8):807-16.

20. Peixoto C, Prado CHO, Rodrigues (P, Cheda JND, Mota LBT, Veras AB. Impacto do perfil clínico e sociodemográfico na adesão ao tratamento de pacientes de um Centro de Atenção Psicossocial a Usuários de Álcool e Drogas (CAPSad). J Bras Psiquiatr. 2010;59(4):317-21.

21. Dawson DA, Li TK, Grant BF. A prospective study of risk drinking: at risk for what? Drug Alcohol Depend. 2008;95(1-2):62-72.

22. van der Meer Sanchez Z, Nappo SA. Intervenção religiosa na recuperação de dependentes de drogas. Rev Saude Publica. 2008;42(2):265-72.

23. Levitan RD, Parikh SV, Lesage AD, Hegadoren KM, Adams M, Kennedy SH, et al. Major depression in individuals with a history of childhood physical or sexual abuse: relationship to neurovegetative features, mania, and gender. Am J Psychiatry. 1998;155(12):1746-52.

24. Johnson JG, Cohen P, Brown J, Smailes EM, Bernstein DP. Childhood maltreatment increases risk for personality disorders during early adulthood. Arch Gen Psychiatry. 1999;56(7):600-6.

25. Johnson JG, Cohen P, Gould MS, Kasen S, Brown J, Brook, JS. Childhood adversities, interpersonal difficulties, and risk for suicide attempts during late adolescence and early adulthood. Arch Gen Psychiatry. 2002;59(8):741-9.

26. Dube SR, Felitti VJ, Dong M, Chapman DP, Giles WH, Anda RF. Childhood abuse, neglect, and household dysfunction and the risk of illicit drug use: the adverse childhood experiences study. Pediatrics. 2003;111(3):564-72.

27. Kessler F, Von Diemen L, Seganfredo AC, Brandão I, De Saibro P, Scheidt B, et al. Psicodinâmica do adolescente envolvido com drogas. Rev Psiquiatr Rio Gd Sul. 2003;25(Supl 1): 33-41.

28. Elbogen EB, Johnson SC. The intricate link between violence and mental disorder. Results from the National Epidemiologic Survey on Alcohol and Related Conditions. Arch Gen Psychiatry. 2009;66(2):152-61.

29. Coêlho BM, Andrade LH, Guarniero FB, Wang YP. The influence of the comorbidity between depression and alcohol use disorder on suicidal behaviors in the São Paulo Epidemiologic Catchment Area Study, Brazil. Rev Bras Psiquiatr. 2010;32(4):396-408.

30. Bolton J, Cox B, Clara I, Sareen J. Use of alcohol and drugs to self-medicate anxiety disorders in a nationally representative sample. J Nerv Ment Dis. 2006;194(11):818-25. 